\section{Higher Technological Education in Britain}

THE University Grants Committee has appointed a sub-committee to advise it on matters affecting technology in the universities of Great Britain, and to consider questions of higher technological education in consultation with the National Advisory Council on Education for Industry and Commerce, appointed by the Ministry of Education. The subcommittee consists of : Dr. A. E. Trueman (chairman), Prof. J. F. Baker, Sir Alan Barlow, H. W. Cremer, Sir Charles Darwin, Sir Peter Innes, Prof. Willis Jackson, Sir Andrew McCance, Prof. Andrew Robertson, Prof. J. B. Speakman, Sir Raymond Streat, Sir Henry Tizard, and Sir Charles Ellis.

\section{B.C.U.R.A. Quarterly Gazette}

THE B.C.U.R.A. Quarterly Gazette-a now publication of the British Coal Utilization Research Association-is designed to give a more colourful account of the Association's work and to serve a wider range of readers than a rigorously scientific journal. To factual accounts of research and development projects, it will add a running commentary on the Association's staff and their activities. The circulation will not be limited to members only. The first number contains a survey by Sir Charles Ellis, president of the Council, as it finds itself in a nationalized coal industry, covering its members, staff, accommodation, work and prospects. There follow articles on technical achievements in course of development. B.C.U.R.A. Patent No. 1 describes the down jet furnace, which employs a revolutionary system of combustion of solid fuels. Normal combustion on a grate is beset by limitations owing to the presence of ash and volatile matter in the fuel. These are avoided by the new technique, which provides freedom to work at greater intensities and for longer durations. The exploitation of these ideas is only in its infancy. Another item deals with the Association's work on domestic heating by open coal fires, which normally radiate not more than 25 per cent of the heat of combustion. Work in past years has shown the possibility of increasing this by one or other method-especially by supplementing radiation with heat convection. To-day the consumers' progress towards fuel economy is limited by lack of availability of efficient appliances. Sometimes these are too costly or even only to be obtained in a new house. The article describes a new inset fire which can be fitted into an existing grate at a moderate cost. It is designed by Mr. J. S. Hales and Mr. T. W. Grieve and claimed to be capable of high thermal efficiencies. When burning normal house coal, the total output of heat-by radiation and convection combined-reached 37 per cent; with coke, the figure reached 48 per cent of the heat of combustion. In addition, by reducing the flow of hee,t up the chimney to one change per hour, draughts are minimized and comfort improved.

\section{Medical Group Practice in the United States}

THE review of the development and characteristics of Medical Group Practice in the United States which Political and Economic Planning has issued as Broadsheet No. 274 is of special interest in view of the obligations placed on local authorities in Britain under the National Health Service Act to provide, equip and maintain health centres staffed and run by medical practitioners working as a team. The survey shows that American group practice aims at providing a full general and specialist service, including, if possible, in-patient treatment, and in the United States the term is applied to almost any form of organised medical team-work. The main incentives appear to be the inability of individual practitioners to provide a sufficiently complete service, the desire for professional co-operation among medical men and the need to reduce the cost of medical care by decreasing overhead expenditure and bringing specialist and hospital services to undeveloped areas. The main criteria are organised teamwork and pooling of income. Day-to-day consultations are supplemented by staff meetings, good record systems, and sometimes also by democratic methods of administration. Groups show much interest in keeping their members up to date and developing their skills, for example, by good libraries, paid annual study leave, and systematic training of junior members. Financial competition within the group not only hinders team-work but also results in friction, and no solution has yet been found for the problem of assessing financially the diverse and constantly changing ability of physicians. The election of group members is of the highest importance and should be done by the medical men them. selves. Some are temperamentally unsuited for group work and should be excluded. Good group practice may have a beneficial influence on medical standards over a wide area; but in view of the important differences in social background, in the development of health services and in the organisation of the medical profession in the United States, careful consideration will be necessary before the lessons of American experience can be applied to Britain.

\section{British Trust for Ornithology}

THE work of the British Trust for Ornithology (91 Banbury Road, Oxford) is described in the fourteenth annual report which has recently been issued. Much useful information has been collected from the hatching and fledging inquiry and will be included in the new edition of the "Handbook of British Birds". A sample census of heronries showed that large decreases were recorded in every considerable area and in the majority of individual heronries; this was almost certainly due to the extreme severity of the winter. The black redstart inquiry showed that, up to the end of the year, sixteen pairs were reported to have lived in the south of England. Other inquiries have been made into the behaviour of tits with milk-bottles and the nocturnal activities of redwings; but probably the most popular was the watch for swifts on May 11, 1947. Five hundred observers made reports on the movements of about five thousand birds, three out of every four of whom were headed north. Above a line drawn from the Wash to the Severn this northward surge was especially marked, and in south-west Devon several parties of swifts were seen to come in from the sea and to proceed inland.

\section{Megalithic Tombs in Scotland and Ireland}

Prof. Gordon CHILdE's present ideas on the Megalithic tombs in Scotland and Ireland are put on record in a paper read before the Glasgow Archæological Society (Trans., 11 ; 1947). Recent discoveries have caused him to modify some details of his exposo made in the same publication for 1931. No longer, for example, is "the priority of Scottish passage 